\title{
UMA ANÁLISE DO SETOR DE DISTRIBUIÇÃO DE FLORES E PLANTAS ORNAMENTAIS NO ESTADO DO RIO DE JANEIRO
}

\author{
Viviani Silva Lirio ${ }^{1}$ \\ Carlos Arthur Barbosa Silva ${ }^{2}$ \\ Brício dos Santos Reis ${ }^{3}$ \\ Danilo Rolim Dias de Aguiar ${ }^{4}$ \\ Ângela Cristina Stringheta ${ }^{5}$
}

\begin{abstract}
Resumo - Uma das principais características da produção de flores e plantas ornamentais é que esta constitui atividade típica de pequenos produtores. Embora a floricultura brasileira venha se expandindo em áreas menos tradicionais como o Nordeste do país, a maior parte da produção ainda se concentra nas regiões Sul e Sudeste, e os dados sobre a distribuição de flores no Brasil indicam o estado de São Paulo como principal centro da produção nacional. O estado do Rio de Janeiro tem-se destacado, nesse contexto, como região potencial de expansão da produção e comercialização de flores e plantas ornamentais, com destaque para as variedades tropicais, de crescente aceitação internacional.Este trabalho analisa o segmento de distribuição de flores e plantas ornamentais no Rio de Janeiro, tendo por referência conceitual o enfoque sistêmico de produto (Commodity Systems Approach). Para consecução da pesquisa, foram realizados amplos levantamentos secundário e primário junto aos principais agentes que atuam no segmento de distribuição de flores no Rio de Janeiro. Os resultados obtidos indicam que os principais entraves ao desempenho do setor estão relacionados com as relações de mercado vigentes e com os aspectos gerenciais.
\end{abstract}

Palavras-chave: Floricultura, cadeias produtivas, Rio de Janeiro.

\footnotetext{
${ }^{1}$ Doutora em Economia Rural pela Universidade Federal de Viçosa (UFV), Professora da UFV. Viçosa - MG. CEP 36570-000. E-mail: vslirio@mail.ufv.br.

${ }^{2}$ Doutor em Economia Agrícola pela Michigan State University, Professor da UFV. E-mail: carthur@mail.ufv.br.

${ }^{3}$ Doutor em Economia Rural pela Universidade Federal de Viçosa (UFV), Professor da UFV. E-mail: bricio@ufv.br.

${ }^{4}$ Doutor pela USP, Professor da UFV. E-mail: danilo@ufv.br.

${ }^{5}$ Doutora e Professora da UFV. E-mail: angelaco@ufv.br.

Recebido em 28/03/2003 - Aceito em 06/05/2003
} 


\section{Introdução}

Dentre os segmentos produtivos agroindustriais que têm se destacado, de forma crescente, nos cenários nacional e internacional, a floricultura mostra-se como um dos mais dinâmicos e promissores. No caso brasileiro, embora a base produtiva ainda seja pequena, se confrontada ao potencial de exploração da atividade, as taxas de crescimento apresentadas pelo segmento, nos últimos anos, superam, expressivamente, os níveis médios de setores tradicionais.

Além disso, a atividade é desenvolvida, na maioria das vezes, por pequenos e microempresários que empregam quantidade expressiva de trabalhadores. Tal fato mostra a importância intrínseca da produção e distribuição de flores e plantas ornamentais, como atividade que contribui para a minimização da evasão no setor agrário e para a melhoria da qualidade de vida do trabalhador rural. Em que pese o aspecto econômico envolvido na ampliação desse mercado, as perspectivas e vantagens, sob o prisma social, são igualmente promissoras.

Todavia, como atividade produtiva ainda em consolidação no Brasil, a floricultura ${ }^{6}$ requer cuidados adicionais na organização das formas de coordenação por ela requisitadas. No Brasil, esse segmento se destaca, principalmente, nos estados de São Paulo, Minas Gerais, Rio de Janeiro, Rio Grande do Sul, Santa Catarina, Bahia, Ceará, Pernambuco, Alagoas e Amazonas. Embora se considerem as perspectivas otimistas do futuro desse segmento, uma das primeiras constatações, ao se analisar a cadeia produtiva das flores e plantas ornamentais no Brasil, refere-se à crônica falta de dados organizados a respeito do setor, agravada pela inconsistência comparativa das informações procedentes de fontes alternativas.

\footnotetext{
${ }^{6}$ Entendida, aqui, em seu sentido mais amplo, abrange o cultivo de flores e plantas ornamentais, destinadas aos mais distintos usos e formas de apresentação.
} 
$\mathrm{Na}$ realidade, a carência de informações pode ser interpretada como decorrente da baixa organização do setor no Brasil, reflexo da ainda frágil coesão entre os diferentes elos da sua cadeia produtiva. Contudo, ao mesmo tempo que esse fato constitui elemento comprometedor da eficiência e da competitividade dos diversos agentes envolvidos nas atividades do setor, é também um estímulo ao desenvolvimento de pesquisas na área de flores e plantas ornamentais, principalmente se considerada a reconhecida riqueza da biodiversidade da flora brasileira, com destaque para esse ainda pouco explorado segmento produtivo.

A partir do exposto, é possível concluir que, principalmente em virtude da estrutura da cadeia produtiva das flores e plantas ornamentais, os benefícios gerados a partir de investimentos e melhorias organizacionais nesse segmento são bastante expressivos. Em virtude da interdependência dos elos da cadeia produtiva, a unidade de produção de flores encontrase interligada a diversos outros segmentos a montante (empresas fornecedoras de mudas e sementes, máquinas e embalagens, dentre outros insumos produtivos) e a jusante (atacadistas, intermediários de natureza diversa, floriculturas, lojas de ornamentação e eventos, entre outros). Entretanto, permeando essa relação direta, existem outros elementos capazes de afetar a eficiência e a competitividade da cadeia produtiva.

Assim, os objetivos centrais desta pesquisa são: (a) Caracterizar a estrutura e o funcionamento do segmento de distribuição de flores e plantas ornamentais no Rio de Janeiro, e (b) Identificar e avaliar os principais direcionadores que condicionam a eficiência e a competitividade desse segmento.

\section{Procedimentos metodológicos}

Os estudos sobre cadeias produtivas agroindustriais têm sido realizados a partir de diferentes abordagens metodológicas que contemplam desde simples estudos exploratórios até complexas análises quantitativas e qualitativas. A opção metodológica, assim, é função dos objetivos da análise e do referencial conceitual adotado, mas não deixa de se preocupar com considerações sobre a disponibilidade de recursos físicos, financeiros e 
humanos e as expectativas dos seus resultados e de sua formatação final.

Neste estudo, a metodologia de análise toma por referência conceitual o enfoque sistêmico de produto (Commodity Systems Approach), bastante utilizado na construção de diversos diagnósticos de cadeias produtivas agroindustriais, tendo por característica central seu viés qualitativo, bastante adequado à identificação de entraves na proposição de medidas corretivas que visem ao aumento da eficiência e competitividade. $\mathrm{O}$ enfoque, apesar de considerar de fundamental importância a construção de uma base sólida de informações acerca de cada segmento analisado, é essencialmente sistêmico.

Nessa abordagem, segundo Silva et al. (1999), um sistema é compreendido por dois aspectos básicos: uma coleção de elementos e uma rede de relações funcionais que atuam, em conjunto, no alcance de algum propósito determinado. De forma geral, esses elementos interagem por meio de ligações dinâmicas que envolvem intercâmbio de estímulos, informações ou outros fatores não-específicos. As análises de cadeias agroindustriais, portanto, beneficiam-se dessa visão conjunta, uma vez que sua eficiência e sua competitividade são frutos do bom desempenho de cada um de seus elos constitutivos.

Assim, com vistas no alcance de tais propósitos, este trabalho utilizou, como método de pesquisa, informações de fontes secundárias, combinadas com entrevistas semi-estruturadas, mediante um processo de amostragem intencional. Trata-se de abordagem metodológica que integra o conjunto de métodos de "rapid appraisal", frequientemente empregado em trabalhos desta natureza por entidades internacionais como o Banco Mundial, USAID, IICA e ILRI, ente outras. ${ }^{7}$ Esse processo, em análises de cadeias produtivas, vem sendo utilizado com sucesso, uma vez que a característica eminentemente qualitativa da pesquisa exige a contribuição dos principais atores de cada cadeia analisada.

Uma das vantagens do uso de entrevistas semi-estruturadas é que, me-

${ }^{7}$ Ver, a respeito, Kumar (1993). 
diante essa prática, a coleta de informações é relativamente rápida. Entretanto, é preciso destacar que o levantamento de informações por meio dessa prática metodológica possui também algumas limitações. Como os métodos de avaliação ocorrem após os eventos, os participantes podem esquecer-se de informações importantes ou, se o questionário for muito extenso, podem respondê-los superficialmente (Trochim, 2002). Assim, a validação das informações obtidas de especialistas no setor produtivo analisado torna-se de extrema relevância e fundamental para a consistência das conclusões da pesquisa.

Para avaliação dos padrões de eficiência da cadeia produtiva, o estudo tomou por base a metodologia originalmente proposta por Van Duren et al. (1993), adaptada por pesquisadores da UFV e da UFSCar (Silva e Batalha, 1999). Este enfoque, já utilizado em diagnósticos de cadeias produtivas agroindustriais, considera que a eficiência em um sistema produtivo seja determinada por fatores diversos, sobre os quais é possível, ou não, o exercício de controle pelas empresas ou pelo governo. Assim, cada elemento será primeiramente classificado como controlável, quase-controlável ou não-controlável pelos agentes que participam da cadeia produtiva analisada.

Em seguida, esses fatores, aqui classificados como direcionadores, foram agrupados em seis grandes blocos: "tecnologia", "gestão", "relações de mercado", "insumos", "estrutura de mercado" e "ambiente institucional". A partir disso, os direcionadores foram desdobrados em subfatores, identificados e analisados quanto à intensidade com que contribuem, favorável ou desfavoravelmente, para a eficiência do sistema ${ }^{8}$. Assim, o direcionador "tecnologia" pode ser, por exemplo, desdobrado nos subfatores assistência técnica, tecnologia disponível, etc.

A partir das informações coletadas nas entrevistas e na pesquisa preliminar (revisão de literatura), cada subfator receberá uma pontuação, que será orientada pela escala de Likert. Para agregar as avaliações dos subfatores ao nível dos direcionadores, a escala qualitativa recebeu

${ }^{8}$ Maiores informações podem ser encontradas no SEBRAE (2001). 
uma transformação numérica no intervalo de -2 a +2 , com gradação unitária ${ }^{9}$. Atribuíram-se, ainda, pesos diferenciados aos subfatores, pois se reconhece que estes tenham impactos não-uniformes no resultado da avaliação de cada direcionador. Com esse procedimento, a avaliação final dos direcionadores é dada pela fórmula;

$$
Y=\sum_{i=1}^{n} Z_{i} W_{i}
$$

em que

$Y=$ avaliação final do direcionador;

$Z_{i}=$ avaliação dada ao subfator $\mathrm{i}$;

$W_{i}=$ peso atribuído ao subfator $\mathrm{i}$;

$n=$ número de subfatores constituintes do direcionador;

A partir desse procedimento, torna-se possível a elaboração de gráficos que ilustram, de forma condensada, os resultados finais da avaliação. $\mathrm{Na}$ verdade, o cruzamento dos dados disponíveis na forma tabular e sua posterior formatação gráfica permitem a identificação dos principais estrangulamentos existentes na cadeia produtiva e a construção de proposições para sua superação.

\section{Resultados e discussão}

3.1. Competitividade do setor de distribuição de flores e plantas em vaso no Rio de Janeiro

Os problemas que afetam o desempenho da distribuição de flores e plantas ornamentais do Rio de Janeiro afetam, diretamente, a competitividade

\footnotetext{
${ }^{9}$ Conforme ressaltado por Silva e Batalha (1999), “..a rigor, o uso de escalas como a aqui adotada, permite, tão somente, o ordenamento e classificação relativa da intensidade dos subfatores analisados, não sendo totalmente apropriado o tratamento quantitativo dos valores atribuídos. No entanto...é prática usual nas Ciências Sociais a suposição que medidas ordinais, como a aqui proposta, são aproximações de intervalos iguais de medição". Os mesmos autores citam trabalhos que dão suporte conceitual e empregam procedimentos similares ao seguido nesta avaliação.
} 
da cadeia produtiva. Neste estudo, buscou-se identificar o principais entraves ao desempenho, os quais são aqui resumidos.

A falta de padronização dos produtos foi apontada como a causa das expressivas disfunções no sistema de distribuição. De fato, apesar dos esforços do Instituto Brasileiro de Floricultura - IBRAFLOR, no intuito de criar regras que determinem um padrão de qualidade para comercialização de flores e plantas ornamentais no país, o comércio varejista do Rio de Janeiro não utiliza nenhum tipo de padronização de seus produtos. Essa realidade, na visão de alguns entrevistados neste trabalho, dificulta o desenvolvimento de modalidades alternativas de comercialização, como as vendas on line (via internet), uma vez que o consumidor não tem garantias da qualidade e das características do produto que está adquirindo. A própria aquisição de flores por parte dos lojistas poderia ser facilitada pela implantação de um sistema único de classificação, o que melhoraria o escoamento da produção e contribuiria para a redução de custos no processo de distribuição. Esses benefícios poderiam gerar menores preços e, conseqüentemente, estimular o consumo interno.

Quanto às técnicas de conservação das flores e plantas nos estabelecimentos varejistas, estas configuram outro foco de dificuldade. Nota-se que a maioria dos entrevistados utiliza apenas câmaras frias para manter nível adequado de temperatura, embora o ideal seja a utilização de máquinas "evaporadoras" que, além de propiciar temperatura condizente com as necessidades das plantas, garantiriam a umidade necessária para sua conservação, por um período de tempo mais longo. Apesar dessas necessidades, alguns estabelecimentos, a exemplo dos quiosques ${ }^{10}$, não empregam técnicas de resfriamento (as plantas em vaso são, normalmente, mais resistentes), mantendo a qualidade de seus produtos com a utilização de procedimentos básicos de conservação, como a troca de água (pelo menos duas vezes por dia), limpeza e corte adequado das plantas, etc., que

\footnotetext{
${ }^{10}$ Pequenos varejistas que comercializam plantas de vaso em estruturas construídas nas ruas e avenidas do Rio de Janeiro e que atendem, em sua maioria, consumidores ocasionais. Foram estimulados pela prefeitura, mediante incentivos fiscais, com o objetivo de embelezar a cidade. Não estão autorizados a vender flores de corte e sua principal característica é a praticidade do atendimento, devido à localização.
} 
são complementares nas floriculturas de maior porte ${ }^{11}$. As plantas mais sensíveis são mantidas dentro das lojas, onde, normalmente, aparelhos de ar-condicionado propiciam temperaturas mais amenas.

No caso específico da única central atacadista do Rio de Janeiro, a CADEG, os produtores fluminenses comercializam seus produtos nos próprios caminhões, que ficam estacionados no pátio da instituição. Esse tipo de procedimento não garante maiores cuidados com o produto, visto que prejudica a aparência e a durabilidade deste. Alguns atacadistas possuem boxes fechados, com câmaras frias e controle de temperatura e umidade. Entretanto, a grande maioria dos agentes que distribuem seus produtos na CADEG não emprega tecnologia adequada no processo de conservação de flores e plantas em seu ponto de venda. Os chamados "pirangueiros" constituem um bom exemplo, pois são caracterizados pela baixa qualidade do produto que comercializam e por trabalharem na informalidade, não possuindo, sequer, estrutura mínima para conservação das flores e plantas.

No que diz respeito ao transporte dos produtos, percebe-se que as floriculturas utilizam, em sua maioria, caminhões próprios e refrigerados para carretos de longa distância (compras realizadas em São Paulo, por exemplo) e veículos comuns na compra e entrega de flores na própria cidade. Esse procedimento parece atender às necessidades daquelas empresas que adquirem diretamente suas mercadorias e possuem serviços de entrega em domicílio. As unidades empresariais que não têm possibilidade de transportar os produtos adquiridos utilizam, normalmente, o serviço de atravessadores para seu abastecimento, que possuem estrutura de transporte adequada, com veículos refrigerados e planejamento das viagens (realizadas, normalmente, à noite). O único empecilho, nesse último caso, é o aumento do custo, mas que não chaga a constituir um entrave significativo.

Com relação à tecnologia da informação, percebe-se que as unidades empresariais encontram muitas dificuldades no emprego de técnicas

\footnotetext{
${ }^{11}$ Mesmo nesse tipo de estabelecimento, não se verifica a utilização de soluções de condicionamento (pulsing) para garantir maior vida útil às plantas, prática comum nos produtos da Holambra.
} 
informatizadas de controle. A maioria dos estabelecimentos utiliza, apenas, programas genéricos de administração (estoque, contas a receber, etc.), o que impossibilita maior integração entre os diversos elos da cadeia (a troca de informações por meio eletrônico é praticamente inexistente). Essa característica é comum tanto no atacado quanto no varejo.

Em relação aos insumos tanto no segmento varejista quanto no atacadista, os principais insumos dizem respeito aos produtos que são comercializados pelos agentes, ou seja, as próprias flores e plantas em vaso, que podem ser classificadas de acordo com sua origem - as que vêm do Estado do Rio de Janeiro e as importadas das demais unidades federativas do país, principalmente São Paulo. No caso das primeiras, a baixa qualidade é o principal fator de entrave à eficiência do setor de distribuição e, conseqüentemente, de toda a cadeia. Enquanto as flores e plantas produzidas em São Paulo apresentam características satisfatórias (aparência, durabilidade, etc.), devido à eficiência do processo produtivo desenvolvido naquele estado e à organização de seus atores, os produtores fluminenses esbarram na ausência de incentivos para que possam incrementar sua competitividade no cenário nacional e na falta de um espírito cooperativista capaz de propiciar a união de esforços para melhoria de suas condições de trabalho. Exatamente nesse ponto é que os distribuidores atacadistas contribuem para a eficiência do comércio varejista no Rio de Janeiro, uma vez que disponibilizam produtos de qualidade superior àquelas unidades empresariais que não têm condições de arcar com os elevados custos de transporte para complementação de seus estoques. Isso garante maior variedade de flores e plantas para atendimento aos consumidores fluminenses.

No abastecimento do comércio varejista destacam-se três fontes alternativas/complementares de oferta: a CADEG, Central de Distribuição do estado do Rio de Janeiro, responsável pela comercialização de produtos oriundos tanto do próprio estado quanto de São Paulo e de algumas outras regiões; as CEASAS, principalmente a de Campinas, onde muitos comerciantes buscam produtos de melhor qualidade; e os leilões tipo holandês (Veiling), que possuem maior nível de sofisticação, visto que 
os produtos são classificados de acordo com rígido padrão de qualidade. De acordo com alguns entrevistados, os problemas enfrentados pela CADEG são a baixa qualidade dos produtos comercializados e a ausência de uma estrutura eficiente de comercialização. Conforme comentado anteriormente, a falta de organização e planejamento gera grandes variações na oferta de cada produto e instabilidade nos preços, o que prejudica o escoamento da produção e não permite a comercialização de um mix adequado de produtos. Além disso, a informalidade das operações propicia elevado índice de inadimplência.

Outra questão caracterizada como ponto negativo na organização da CADEG diz respeito à atuação, em sua estrutura, de agentes que apenas intermediam o processo de comercialização. De acordo com normas internas, apenas produtores poderiam ter boxes nessa central. No entanto, pôde-se detectar a existência de distribuidores que possuem como única atividade a compra e a venda de plantas e flores, mas que não atuam no segmento produtivo. Já em relação às compras realizadas nas CEASAS e nos leilões, os pontos negativos são custo elevado de transporte, no caso de compras feitas diretamente pelos comerciantes, e maiores preços pagos a atacadistas. Contudo, na visão da maioria dos entrevistados, não podem ser considerados como entraves. A atuação dos intermediários, inclusive, é caracterizada como benéfica, já que esses agentes arcam com custos elevados de transporte e disponibilizam produtos de qualidade àqueles comerciantes que não possuem condições de buscá-los em outras regiões, o que contribui para a eficiência da cadeia.

Quanto à variedade de mercadorias, os estabelecimentos varejistas procuram trabalhar com a mais ampla gama de espécies possível, garantindo, assim, maior fidelidade por parte de seus clientes, que encontram, com facilidade, os produtos adequados às suas necessidades. Essa característica faz com que as floriculturas, em sua maioria, possam ser classificadas como de médio porte, tamanho ideal, na visão de muitos, para atender às exigências do mercado fluminense. Já os quiosques, conforme já comentado, são estabelecimentos de pequeno porte que têm 
como principal atrativo a praticidade de sua localização, embora também procurem trabalhar com mix variado de produtos.

Essas observações não podem ser feitas para os agentes atacadistas no estado, que, normalmente, não possuem escala adequada de trabalho. Muitos vendem seus produtos, conforme já enfatizado, em seus próprios caminhões, que ficam estacionados no pátio da CADEG. A única vantagem estrutural dessa central está em sua localização, privilegiada em termos de acesso às principais rodovias de acesso às regiões produtoras fluminenses e de outros estados da federação.

As floriculturas buscam atender à demanda com flores e plantas oriundas, sobretudo, de produtores localizados no estado de São Paulo. Portanto, as principais fontes de abastecimento são as CEASAS e os leilões tipo holandês (Veilling), sendo as compras realizadas diretamente ou por meio de atacadistas, como já enfatizado. A CADEG é utilizada apenas para complementar o mix de produtos da loja, uma vez que a baixa qualidade das mercadorias e a desorganização são características marcantes dessa instituição.

Já nos quiosques a situação é inversa. A CADEG é a principal fonte de produtos, sendo a oferta complementada por flores e plantas adquiridas nas CEASAS e nos leilões, que chegam até o comerciante pelos intermediários. Esses agentes, conforme já enfatizado anteriormente, contribuem para o abastecimento do mercado fluminense, garantindo maior disponibilidade de produtos e oferta contínua. Entretanto, são considerados prejudiciais aos produtores locais, uma vez que trazem produtos de melhor qualidade, a preços menores ou equivalentes. Nesse contexto, as relações entre os agentes do segmento de distribuição podem ser consideradas informais, não se verificando a existência de contratos entre produtores, atacadistas e varejistas. Normalmente, esses últimos são fiéis a seus fornecedores, o que garante melhores condições de pagamento, devido à relação de confiança estabelecida pela fidelidade ${ }^{12}$. A troca

${ }^{12}$ Devido a problemas de inadimplência no passado, os comerciantes do Rio de Janeiro que não possuem relação de fidelidade com seus fornecedores têm que pagar suas compras, normalmente, a vista. 
de informações também é informal, com encontros ocasionais para discussão de tendências e oportunidades de negócios.

No que diz respeito à mão-de-obra utilizada no processo de comercialização de flores e plantas em vaso no estado do Rio de Janeiro, tanto no atacado quanto no varejo, percebe-se que o nível de qualificação dos profissionais é baixo, já que não existem cursos destinados à especialização de trabalhadores para o setor. Na maioria dos estabelecimentos visitados, o próprio proprietário é quem treina seus funcionários que vêm, normalmente, de estabelecimentos comerciais diversos - para manusear as mercadorias. Por um lado, esse procedimento garante menores custos, mas, por outro, pode gerar maiores perdas e insatisfação de clientes, uma vez que os atendentes não possuem conhecimentos técnicos adequados sobre o produto que estão vendendo.

Esse problema de baixa qualificação da mão-de-obra associa-se à completa ausência de planejamento estratégico nas unidades de comércio varejista do estado. Essa característica é ainda mais marcante na central atacadista, onde os produtores/distribuidores não realizam nenhum tipo de análise prévia para organização de suas atividades, gerando, conforme já comentado, grandes variações de oferta e de preço. As decisões sobre compra de mercadorias e investimentos são tomadas com base no feeling dos administradores, ou seja, não há um sistema eficaz de apoio à decisão. As informações contábeis são tratadas como mera formalidade fiscal, e não constituem instrumental para subsidiar o processo de gerenciamento do negócio.

Nesse contexto, poucos são os empresários que utilizam, adequadamente, instrumentos de marketing apropriados. A maioria das empresas entrevistadas faz uso apenas de recursos de divulgação de seus produtos, como folhetos distribuídos nas ruas e, eventualmente, propagandas em jornais de bairro e em espaços de certo destaque nas "páginas amarelas" das listas telefônicas. Outra prática comum é a distribuição de brindes (imãs de geladeira, calendários, etc.) para os clientes. Esse tipo de estratégia está muito aquém do conceito de marketing tradicional, que 
envolve, além da propaganda, técnicas de atendimento ao cliente, organização do espaço comercial (layout), promoções, entre outros instrumentos que objetivam o incremento de vendas. $\mathrm{O}$ processo de adição de valor aos produtos é um dos elementos importantes nesse contexto; entretanto, consiste, basicamente, em criação de arranjos para ornamentação e varia de acordo com a criatividade de proprietários e funcionários da empresa.

\subsubsection{Síntese dos direcionadores da eficiência do setor de distribui- ção de flores e plantas em vaso no Rio de Janeiro}

A Figura 1 sintetiza os comentários sobre o desempenho do setor de distribuição de flores no Rio de Janeiro. Como é possível observar, apenas o direcionador estrutura de mercado contribui, de forma positiva, para a eficiência do segmento de distribuição da cadeia de flores e plantas em vaso no Rio de Janeiro, mesmo assim, apenas para o subsegmento do varejo. Essa representação retrata a situação precária do processo de comercialização desses produtos no Estado.

No que tange à tecnologia utilizada, a falta de padronização e a ausência de técnicas adequadas de conservação do produto no ponto de venda são os principais responsáveis pelo sinal negativo do indicador. A nãoutilização de sistemas de informação adequados às necessidades do processo de comercialização também contribui para o mal resultado alcançado. Apenas o emprego de caminhões adequados ao transporte das plantas apresenta-se como subfator favorável ao desempenho da cadeia.

Quanto aos insumos, a baixa qualidade das flores produzidas no Rio de Janeiro é fator fundamental para a ineficiência do sistema de distribuição, uma vez que esses produtos, mais acessíveis aos comerciantes devido a fatores geográficos, não atendem, de forma satisfatória, às necessidades dos consumidores do Estado. Nesse contexto, a maior parte do mercado carioca é abastecida por produtores paulistas que apresentam nível de 
tecnificação superior e melhor organização de seu processo produtivo, o que lhes garante maior competitividade no cenário nacional. Os demais insumos, com exceção das embalagens para transporte, que têm custo elevado, não constituem à eficiência da cadeia.

Em relação à estrutura de mercado, o bom desempenho do subsegmento varejista está atrelado a fatores como mix de produtos e escala, adequados às necessidades de consumo, localização privilegiada dos pontos de venda e baixo índice de concentração. Já no subsegmento atacadista, a desorganização do processo de comercialização, aliada à ausência de um planejamento de oferta que garanta o fornecimento de variedades adequadas aos comerciantes, acaba por dificultar o desempenho do setor.

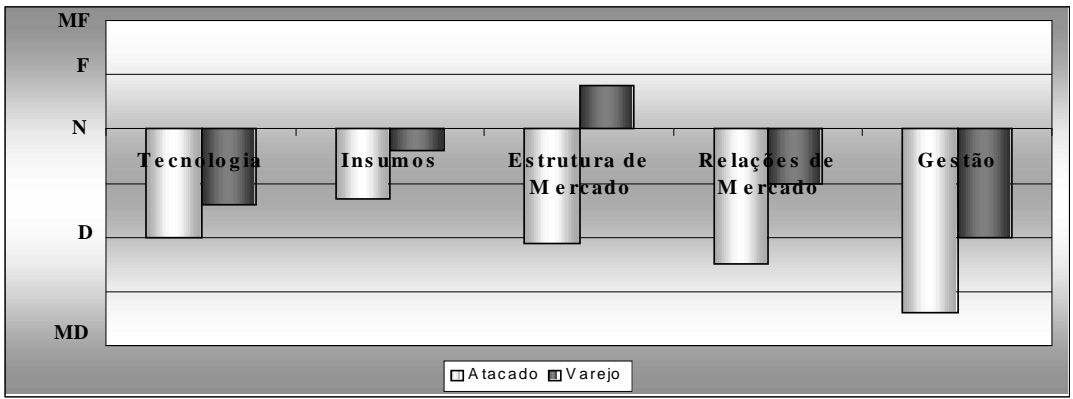

Fonte: Resultados da pesquisa.

Figura 1 - Indicadores de eficiência da distribuição (atacado e varejo) de flores de corte e plantas em vaso.

No que se refere às relações entre os agentes, o segmento é prejudicado, sobretudo, pela ausência de integração e, consequientemente, pela não formação de parcerias e alianças capazes de garantir maior eficiência ao processo de distribuição dos produtos. Também não existem regras claras de formação de preços, o que causa uma disparidade muito grande entre os valores cobrados por produtos similares em diferentes unidades empresariais. Além disso, a falta de padronização das flores e plantas comercializadas dificulta a implantação de sistemas informatizados de compra e venda. 
Por fim, quanto à gestão empresarial, o subsegmento atacadista tem como principal entrave a ausência de controles gerenciais adequados, dada a baixa utilização da informática e de relatórios financeiros como base de informações para a tomada de decisão na empresa. No varejo, além desse problema, a mão-de-obra pouco qualificada e a ausência de políticas adequadas de promoção de vendas são os principais fatores negativos no processo gerencial, o que faz com que esse indicador seja um dos mais significativos na explicação da ineficiência do segmento de distribuição de flores e plantas em vaso no Rio de Janeiro.

\subsection{Desempenho do setor de distribuição de plantas ornamentais no Rio de Janeiro}

A venda das plantas ornamentais se dá, quase que exclusivamente, dentro das próprias chácaras (ou hortos), situadas na região periférica ao município do Rio de Janeiro. Assim, inexiste para esses produtos uma central atacadista nos moldes da CADEG, ou mesmo galpões coletivos de venda. Essa é, aliás, uma importante reivindicação dos distribuidores, quase sempre os próprios produtores ${ }^{13}$. Segundo os entrevistados, em passado recente houve um esforço conjunto pela criação de uma central de distribuição ampla, com câmaras refrigeradas (para as plantas que assim o exijam), espaços com controle de umidade para bromélias e orquídeas, dentre outros, suficientemente estruturada e capaz de alavancar o setor. O projeto, segundo os entrevistados, chegou a ser devidamente oficializado, contudo, fatores políticos e institucionais embargaram sua consecução.

Embora frustrados em suas expectativas, alguns entrevistados afirmaram que a localização da pretensa central, embora acertada do ponto de vista estético, não o era do ponto de vista prático. Segundo eles, o ideal seria que tal estrutura se localizasse mais próxima a Campo Grande, ou

\footnotetext{
${ }^{13}$ Essa foi uma afirmação praticamente consensual. O único agente que, embora tenha demonstrado apoio à idéia, não afirmou depender efetivamente da montagem da venda coletiva foi o Horto das Palmeiras. Esse posicionamento, contudo, é compreensível quanto se observa que as vendas da empresa direcionam-se a um público mais específico e seletivo que as demais.
} 
em região intermediária que favorecesse tanto os produtores de plantas ornamentais quanto os de flores de corte e plantas de vaso.

No que diz respeito ao cuidado com a qualidade do produto apresentado ao mercado, em aproximadamente $80 \%$ das propriedades visitadas foi possível constatar o uso de algum tipo tecnologia de conservação, incluindo a limpeza das folhas com produtos específicos para acentuar o brilho e a transferência das plantas em época de comercialização, para regiões sombreadas. Além disso, em cerca de metade dos estabelecimentos visitados usava-se a informatização.

Tal procedimento, contudo, quase sempre se restringe à manutenção de cadastros de clientes e emissão de recibos de venda, sem que se percebam maiores pretensões de ampliação do uso do maquinário disponível para formação de bancos de dados (fluxos de compra e venda, acompanhamento dos volumes importados de outras chácaras/produzidos na propriedade, etc.) ou venda pela Internet. Além disso, foi possível perceber também que, no tocante à tecnologia de informação, as empresas não têm utilizado essa alternativa no relacionamento com seus fornecedores.

Ademais, por tratar-se de plantas bastante resistentes, não há necessidade de uso de galpões refrigerados. Entretanto, quase todas as empresas possuem estufas (algumas climatizadas) com controle de umidade, as quais servem, inclusive, como espécie de packing house. Em outras palavras, se há exigência, por parte de algum cliente, de que as plantas recebam algum tipo de tratamento especial (inclui arranjos em cestas de madeira e plantio conjunto em xaxins, comuns para as bromélias), as estufas são utilizadas nessa finalidade.

Quanto à disponibilidade das plantas no Rio de Janeiro, esta não pode ser considerada um problema, pelo menos em termos gerais. É certo que, segundo os entrevistados, periodicamente surgem alguns modismos na área paisagística e, dependendo do tipo da planta que passa a ser demandada, podem surgir problemas relativos ao abastecimento, ao menos temporariamente. O fato é que muitas dessas plantas, em especial 
bromélias e palmeiras, levam bastante tempo até chegarem ao porte desejado, o que faz com que existam esses eventuais descompassos entre a oferta e a demanda local.

Segundo os depoimentos colhidos nas entrevistas, nessas ocasiões, quase sempre o mercado paulista é acionado. Por ser mais expressivo, esse mercado tende a absorver grande parte das 'novidades' apresentadas nas feiras e congressos, em nível nacional e internacional, sendo importante fornecedor das plantas mais utilizadas em cada período.

Os demais insumos utilizados no processo de comercialização (energia, água, vasos, sacos de embalagem, substrato para transferência das plantas para vasos, etc.) não foram classificados como problemáticos, nem em qualidade, nem na disponibilidade e no custo, sendo boa parte oriunda de São Paulo. Contudo, cabe, aqui, uma ressalva quanto à mão-de-obra, que, de acordo com os entrevistados, e aqui o consenso não encontra exceção, é de baixa qualidade, pouco afeita aos tratos qualitativos e extremamente despreparada. Na verdade, o treinamento básico é feito nas próprias empresas, mas existe demanda, bastante expressiva, de cursos de jardinagem no local de trabalho.

O mix de produtos comercializados varia muito entre as empresas. De modo geral, além da venda das plantas, quase todas trabalham também com produtos de jardim. Em alguns locais, foram contratados artesãos para o desenvolvimento de vasos especiais, cestas trançadas etc, que são vendidas no local, além de insumos diversos para jardinagem, tais como vasos de cimento, cerâmica e plástico, pedras de ornamentação, antigüidades, substrato, sacos, ferramentas, adubos, objetos de decoração e mudas. Existe, ainda, a assessoria paisagística, realizada pelo próprio empresário ou familiar (no caso das empresas familiares) ou por profissional habilitado para a atividade. Embora com variado percentual, o valor comercializado com esses produtos é, de acordo com as informações coletadas, bastante representativo.

Por fim, em relação à localização dos estabelecimentos, não foi apresentada nenhuma queixa, a não ser pela péssima qualidade das estradas que 
servem de escoamento da produção e acesso aos consumidores que preferem visitar os hortos. Há de se destacar que a reclamação procede, visto que há muitos buracos e, de tão freqüentes, tem-se a impressão de que se trata de rodovias sem pavimentação. Assim, a questão logística e de transporte, uma das mais relevantes no atual cálculo dos custos envolvidos na distribuição, fica seriamente prejudicada.

No que se refere às relações entre os agentes, vigora, quase exclusivamente, o relacionamento via mercado aberto, no qual o mecanismo de preços coordena as relações entre os empresários dos diversos estágios de comercialização. Apenas em um caso identificado, vigora o sistema contratual, já que a firma entrevistada se responsabiliza pela distribuição dos produtos da empresa paulista mediante pagamento (firmado por contrato) de um percentual do valor das vendas.

Existem, no entanto, parcerias informais entre os empresários. É usual entre os proprietários/distribuidores o acesso aos estoques de plantas, em caso de falta de produto. É igualmente comum a tentativa de efetivar, conjuntamente, as compras (ou ao menos o transporte) de plantas vindas de São Paulo. Assim, a princípio, poder-se-ia dizer que existe rivalidade entre firmas, comum e esperada, em qualquer mercado, mas esta acontece de forma aparentemente salutar, sem que se percebam, de forma explícita, problemas nessa área.

Entretanto, uma leitura mais cuidadosa das respostas dadas durante as entrevistas permite vislumbrar que, em alguns casos, há problemas entre os agentes, principalmente quando se trata de regras de cooperação, da definição de uma meta comum para o setor, de traçar diretrizes ou de estabelecer metas no curto, médio e longo prazo. Além disso, quando se colocam em pauta as relações com produtores de flores de corte e vaso, que comercializam na CADEG, a rivalidade torna-se mais visível, principalmente em seus contornos menos desejáveis.

É preciso citar, no contexto das relações de mercado existentes, a presença da Associação Planta-Rio, que congrega praticamente todos os 
produtores e distribuidores de plantas ornamentais do Rio de Janeiro. A Associação, bastante conhecida, tem buscado ações integrada e tem bastante acesso junto aos associados. Merece destaque o fato de que em vários momentos, durante as entrevistas, foi sentido o desejo de se conseguir estruturar uma cooperativa de crédito mútuo para os participantes do segmento, por ser o acesso a recursos, no entendimento dos entrevistados, um importante entrave à expansão da atividade.

No quesito gestão, o modelo predominante no setor de plantas ornamentais é aquele no qual o próprio empresário se encarrega de gerenciar a compra e a venda das plantas. Embora ocorram aquisições esporádicas por parte de outros agentes (por encomenda), essa não é a prática mais comum. Como a especialização das empresas que vendem o tipo de produto analisado é grande ${ }^{14}$, há bastante conhecimento dos empresários (formal e empírico) sobre as plantas comercializadas, o que aumenta o rigor na seleção de plantas oriundas de outras propriedades, quer sejam da própria região, quer originadas de outro estado, particularmente o paulista.

De fato, embora os gerentes (quase sempre os próprios empresários) nem sempre tenham grau de escolaridade superior, a prática da atividade lhes concede bom conhecimento acerca de suas atividades. Na verdade, a utilização de técnicas e controles tradicionais nas unidades produtoras de plantas ornamentais, no Brasil como um todo, é ainda escassa. Apenas algumas das propriedades visitadas já contam, de alguma forma, com estruturas de controle de custo (normalmente, um simples controle de contas), treinamento de mão-de-obra e outras estruturas de gerenciamento.

Na maior parte dos casos, os processos de recrutamento, seleção e treinamento de profissionais para atuar nas empresas não seguem qualquer rigor. Assim, a maior parte dos profissionais tem, quando muito, apenas experiência na área de horticultura, não possuindo técnicas especiais de

\footnotetext{
${ }^{14}$ Como as plantas ornamentais não são vendidas em lojas sem especialização, como é o caso dos supermercados para as flores de corte e plantas em vaso, a comercialização das plantas é sempre um fator estratégico e muito relevante para os empresários.
} 
manejo com as plantas.

As noções de uso de marketing, enquanto ferramenta indispensável à boa rentabilidade dos pontos de varejo, são pouco utilizadas pelos empresários. Mesmo assim, quando utilizado, o marketing é confundido com propaganda pura e simples (normalmente veiculada em revistas de variada abrangência), o que impede seu uso adequado por parte desses empresários. Na verdade, o marketing deve ser entendido como um conjunto de elementos que buscam satisfazer às necessidades e aos desejos dos clientes atuais e potenciais por meio de processos de troca. Assim, quatro itens devem ser observados prioritariamente, quais sejam, produto, ponto de distribuição, composto promocional e preço.

No caso específico das empresas de distribuição de flores e plantas ornamentais, a compreensão dessas dimensões seria extremamente útil, principalmente tendo em mente o perfil dos consumidores preferenciais. Tal entendimento favoreceria maiores cuidados com as plantas e a manutenção destas em condições adequadas; elevaria o nível de agregação de preços por meio do estímulo à criatividade no uso de arranjos diferenciados e novas variedades; e, por fim, estabeleceria limites um pouco mais precisos aos ganhos unitários pela venda do produto.

Nos aspectos qualitativos, deve-se destacar que uma das firmas já conseguiu a certificação do Selo Verde, cujo alcance estimulará, naturalmente, outras firmas locais a obtê-lo, fazendo com que esse esforço conjunto, com ênfase na qualidade não apenas no produto mas também nos processos, tenha, potencialmente, efeito positivo de extrema relevância.

\subsubsection{Síntese dos direcionadores da eficiência do setor de distribui- ção de plantas ornamentais no Rio de Janeiro}

Conforme comentado neste trabalho, o segmento de distribuição de plantas ornamentais concentra-se no segmento varejista, já que praticamente 
inexistem compras em atacado. Grandes volumes (superiores a mil plantas) são adquiridos esporadicamente e, quando isso é feito, quase sempre a aquisição combina plantas produzidas no Rio de Janeiro e em São Paulo. Assim, os comentários aqui delineados, e sumarizados na Figura 2, referem-se, em exclusivo, à comercialização das plantas junto ao público consumidor, quase sempre constituído de paisagistas.

Dentre os cinco direcionadores considerados, apenas a gestão, como ilustra a Figura 2, foi considerada um entrave à competitividade e eficiência do segmento. Em relação à tecnologia, observou-se, ao longo das entrevistas realizadas, que praticamente inexistem problemas relevantes. Aliás, as características de relativa rusticidade e resistência das plantas garantem menor grau de exigência com o manuseio e acondicionamento destas. Apenas o item tecnologia da informação foi classificado como desfavorável, o que explicita a ausência dessa prática entre os distribuidores de plantas ornamentais, no Rio de Janeiro.

Em relação aos insumos, não foram observados problemas. Ainda que passíveis de aprimoramento, os subfatores considerados foram classificados como favoráveis, com destaque para qualidade e disponibilidade dos produtos oriundos de outros estados (principalmente São Paulo). Na análise relativa à estrutura de mercado, que envolve a observação de subfatores, como localização, porte das firmas e concentração de mercado, também não foram encontrados problemas de realce, o que resultou em uma avaliação global positiva desse indicador.

No que se refere às relações de mercado, embora o resultado global tenha sido favorável, é preciso salientar que a formação de preços, um dos itens computados, foi considerada desfavorável. Na realidade, durante as entrevistas foi possível perceber que os mecanismos tradicionais de formação de preços são pouco utilizados. Há uma espécie de consenso sobre a cobrança do produto, lastreado em informações de preços de outras regiões, sem que se considerem os mecanismos de construção dos preços nestas. Ademais, em alguns momentos, para plantas de valor unitário mais elevado, a disposição a pagar do comprador deter- 
mina, em boa parte, o preço praticado, o que resulta no aumento do preço médio local.

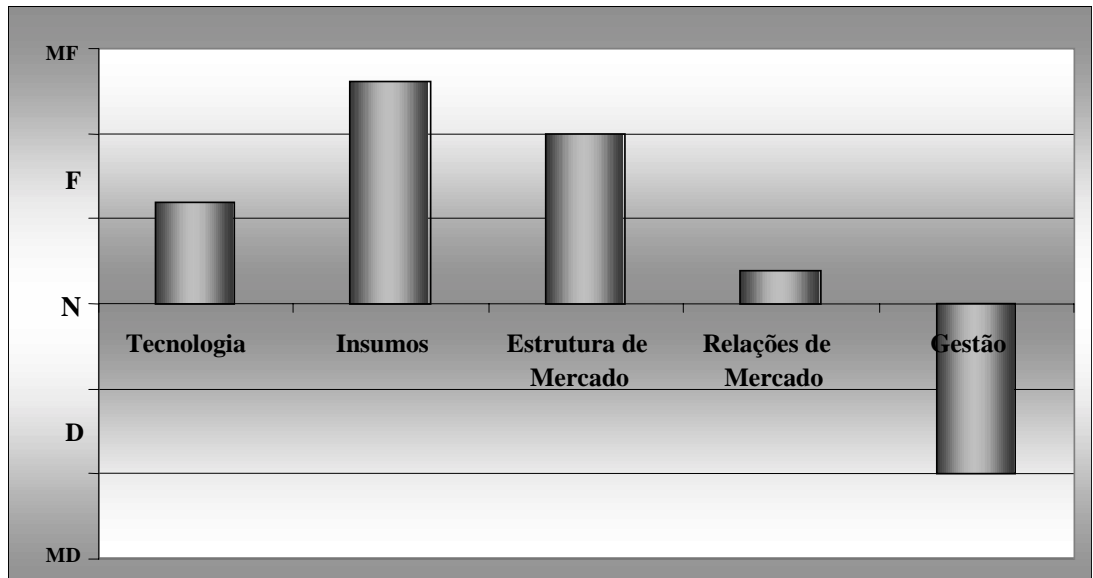

Fonte: Resultados da Pesquisa.

Figura 2 - Eficiência da distribuição (Varejo) de plantas ornamentais no Rio de Janeiro.

O último item analisado, que reúne elementos ligados à gestão da empresa, foi o de pior desempenho. Embora o perfil da organização (quase sempre familiar) e o formato do ponto de venda tenham sido classificados como elementos favoráveis ao bom desempenho do segmento de distribuição de plantas ornamentais, os três quesitos de maior peso receberam classificação desfavorável ou muito desfavorável.

Os itens 'promoção e marketing' e 'gestão dos estoques', classificados como desfavoráveis, devem ser reavaliados, principalmente em termos da atenção a eles destinada. As ações de divulgação do produto, em um período de franca expansão do consumo, são muito tímidas e quase sempre ligadas ao aspecto preço. Os esforços despendidos na divulgação em revistas de paisagismo e decoração, à exceção do Horto das Palmeiras, são pequenos. Assim, a ampliação do incentivo ao consumo, por parte, inclusive, do consumidor de pequeno porte, deve ser objeto de ação mais direta. 
No que se refere à gestão dos estoques, a situação encontrada também foi precária, visto que praticamente inexistem controles sistematizados dos custos de produção e o fluxo financeiro é, de certa forma, tratado informalmente. Embora a situação se apresente com muitas nuances entre as empresas visitadas, é certo que melhorias nesse setor trariam benefícios importantes para a competitividade e eficiência do segmento varejista de plantas de jardim.

\section{Considerações finais}

A observação dos diferentes elementos constitutivos da cadeia de plantas em vaso e ornamentais, no Rio de Janeiro, evidenciou a existência de um importante conjunto de fatores que influem positiva e, ou, negativamente, e em magnitudes distintas, na eficiência desse segmento. No caso do Setor de Distribuição das Flores, os resultados da pesquisa indicam que apenas o direcionador estrutura de mercado contribui, de forma positiva, para a eficiência do segmento de distribuição da cadeia de flores e plantas em vaso no Rio de Janeiro, mesmo assim apenas no subsegmento do varejo. Essa representação retrata a situação precária do processo de comercialização desses produtos no Estado.

O bom desempenho do subsegmento varejista está atrelado a fatores como mix de produtos e escala, adequados às necessidades de consumo; localização privilegiada dos pontos de venda; e baixo índice de concentração. Já no subsegmento atacadista, a desorganização do processo de comercialização, aliada à ausência de um planejamento de oferta que garanta o fornecimento de variedades adequadas aos comerciantes, acaba por dificultar o desempenho do setor.

No caso da Distribuição de Plantas Ornamentais, esta se concentra no segmento varejista, já que praticamente inexistem compras em atacado. Grandes volumes (superiores a mil plantas) são adquiridos esporadicamente e, quando isso é feito, quase sempre a aquisição combina plantas produzidas no Rio de Janeiro e São Paulo. Assim, os comentários aqui 
delineados e sumarizados referem-se, em exclusivo, à comercialização das plantas junto ao público consumidor, nesse caso, quase sempre constituído de paisagistas.

Dentre os cinco direcionadores considerados, apenas a gestão foi avaliada como entrave à competitividade e eficiência do segmento. Embora $\mathrm{o}$ perfil da organização (quase sempre familiar) e o formato do ponto de venda tenham sido classificados como elementos favoráveis ao bom desempenho do segmento de distribuição de plantas ornamentais, os três quesitos de maior peso receberam classificação desfavorável ou muito desfavorável.

Os itens 'promoção e marketing' e 'gestão dos estoques', classificados como desfavoráveis, devem ser reavaliados, principalmente pela atenção a eles destinada. As ações de divulgação do produto, em um período de franca expansão do consumo, são muito tímidas e quase sempre ligadas ao aspecto preço. Os esforços pela divulgação em revistas de paisagismo e decoração, à exceção de apenas uma das empresas entrevistadas, são pequenos, razão pela qual a ampliação do incentivo ao consumo, por parte, inclusive, do consumidor de pequeno porte, deve ser objeto de ação mais direta.

Por fim, os recursos humanos (que envolvem tanto mão-de-obra gerencial quanto operacional) foram o subfator de pior desempenho no segmento, sendo classificado como muito desfavorável à competitividade e eficiência do segmento. De fato, o que se observou foi baixa qualificação da mão-de-obra, principalmente a operacional. Os gerentes, quase sempre os próprios donos das chácaras produtoras, têm boa noção, ainda que empírica, de atendimento, mas houve muitas queixas quanto à qualidade da mão-de-obra disponível para trato direto com as plantas (colheita, embelezamento, empacotamento, etc).

Os empregados, quase sempre pessoas sem qualquer treinamento, acabam recebendo informações básicas dentro das empresas, sem que exista formalização desse processo. Em muitos casos, trata-se de pequenos 
lavradores, que buscam melhoria de renda e, ou, desempregados sem qualquer prática anterior com a agricultura. Assim, esforços que visem qualificar esses trabalhadores em tratos de jardinagem e atendimento básico, uma vez que, eventualmente, eles recebem os clientes, seriam muito proveitosos.

\section{Referências bibliográficas}

AKI, A. Quase tudo o que você gostaria de saber sobre floriculturas. www.mercadodasflores.com.br , 05/09/1999.

AKI, A. O que influencia o consumo de flores. www.mercadodasflores.com.br 04/10/2000.

AKI, A. Algumas informações sobre pesquisas no mercado de flores. www.mercadodasflores.com.br , 04/10/2001.

BONGERS, F.J. Avaliação do Mercado das Flores no Brasil. In.: Congresso Brasileiro de Olericultura, 35. Foz do Iguaçu, Anais. Curitiba:SOB, 1995. p 171-174.

CASTRO, C. E. F. de. Cadeia produtiva de flores e plantas ornamentais. Revista Brasileira de Horticultura Ornamental. Campinas: Sociedade Brasileira de Floricultura e Plantas Ornamentais, 1998, v. 4, n. $^{\circ} 1 / 2$.

KUMAR, K. (Ed.) Rapid Appraisal Methods. The World Bank, Washington, 1993

LORENZI, S. Flores contra o desemprego. In: Jornal do Brasil, 14/04/ 2001.

SILVA, C.A.B. e BATALHA,M.O. Competitividade em Sistemas Agroindustriais: Metodologia e Estudo de Caso. Anais do II Workshop de Gestão de Sistemas Agroalimentares. Ribeirão Preto/SP:1999. Pp 9-21. 
SILVA, C. Textos de Referência do Workshop de Repasse da Metodologia do Programa "SEBRAE - Cadeias Produtivas Agroindustriais", Viçosa, MG, 1999

TROCHIM, W.M.K. Questionários: vantagens e desvantagens. (http:/ /www.ltdi.com.br capturado em 16 de abril de 2002).

VAN DUREN, E., MARTIN, L. \& WESTGREN, R. Assessing the Competitiveness of Canada's Agrifood Industry. Canadian Journal of Agricultural Economics, 39, 1991. p.727-738 